\title{
Testing Cognitive and Interpersonal Asymmetry vs. Symmetry Among Voters in the 2020 Presidential Primaries
}

\author{
Jake Womick $^{1}$, Laura A. King ${ }^{2}$ \\ [1] Department of Psychology \& Neuroscience, University of North Carolina, Chapel Hill, NC, USA. [2] Department of Psychological Science, University of Missouri, \\ Columbia, MO, USA.
}

Journal of Social and Political Psychology, 2021, Vol. 9(2), 592-607, https://doi.org/10.5964/jspp.7771

Received: 2020-07-08 • Accepted: 2021-06-02 • Published (VoR): 2021-11-30

Handling Editor: Alessandro Nai, University of Amsterdam, Amsterdam, The Netherlands

Corresponding Author: Jake Womick, 101 Howell Hall, Chapel Hill, NC 27514, United States. E-mail: jjwzp5@mail.missouri.edu

Supplementary Materials: Data, Materials, Preregistration [see Index of Supplementary Materials]

\begin{abstract}
During the 2020 U.S. Presidential primary season, we measured candidate support and cognitive and interpersonal variables associated with political ideology among 831 U.S. participants. Cognitive style variables included openness to experience, active openminded thinking, dogmatism, and preference for one right answer. Interpersonal variables were compassion and empathy. We modeled candidate support across the political spectrum, ranging from the most conservative to the most liberal (Trump, Bloomberg, Biden, Warren, Sanders), testing competing pre-registered predictions informed by the symmetry and asymmetry perspectives on political ideology. Specifically, we tested whether mean levels on the variables of interest across candidate supporters conformed to patterns consistent with symmetry (i.e., a curvilinear pattern with supporters of relatively extreme candidates being similar to each other relative to supporters of moderate candidates) vs. asymmetry (e.g., linear differences across supporters of liberal vs. conservative candidates). Results broadly supported the asymmetry perspective: Supporters of liberal candidates were generally lower on cognitive rigidity and higher on interpersonal warmth than supporters of conservative candidates. Results and implications are discussed.
\end{abstract}

\section{Keywords}

political ideology, voting behavior, candidate support, election, conservatism, liberalism, cognitive rigidity, interpersonal warmth, dogmatism, compassion

\section{Non-Technical Summary}

\section{Background}

The 2020 U.S. Presidential Primaries offered unique research opportunities because this race was characterized by a large number of Democratic candidates, some of whom were relatively liberal for U.S. politics.

\section{Why was this study done?}

We used this opportunity to address the ongoing asymmetry vs. symmetry debate. This debate concerns whether the key psychological difference between people regards the content of their political views (conservative vs. liberal) or the extremity of their views. 


\section{What did the researchers do and find?}

We focused on cognitive variables representing rigidity and interpersonal variables tapping warmth. In the study, 831 U.S. participants indicated their support for 2020 Primary candidates, and completed measures of cognitive rigidity (openness to experience, active open-minded thinking, dogmatism, preference for one right answer), and interpersonal warmth (compassion, empathy). Generally, we found support for the asymmetry perspective: Supporters of extreme liberals tended to be lowest on cognitive rigidity and highest on interpersonal warmth. Trump supporters were highest on cognitive rigidity and lowest on interpersonal warmth. Supporters of moderates were in the middle of these two groups on the respective variables.

\section{What do these findings mean?}

In contrast to the symmetry perspective, these data do not suggest that extreme liberals and extreme conservatives are more similar than they are different. However, given the potential idiosyncrasies of U.S. politics and the 2020 election, it is important to test similar predictions in other cultural and historical contexts.

The U.S. 2020 Democratic Presidential primary included candidates representing a range of left-wing political views. It thus offered an opportunity to test for psychological differences across supporters of a range of candidates from the relatively far left end of the spectrum (i.e., Sanders and Warren) vs. support for those closer to the center (e.g., Biden and Bloomberg), vs. those on the right (Trump supporters). This context provided an ecologically valid opportunity to address the ongoing asymmetry vs. symmetry debate in political psychology. The asymmetry perspective holds that psychological characteristics share linear associations with political views, for example that cognitive rigidity should be lowest among the most liberal and increase as people become more conservative. In contrast the symmetry perspective focuses on the extremity of views, regardless of their content. From this perspective, extremists should be similarly high on characteristics such as cognitive rigidity, with moderates differing from both groups (U- or inverted U-shaped curves). The presence of relatively extreme left-wing candidates in the Democratic field allowed for a comparison of supporters of candidates along the political spectrum to test these competing predictions.

In the current study, we collected data following Super Tuesday, measuring candidate preferences as well as cognitive and interpersonal characteristics that have been shown to relate to political ideology. We tested competing predictions informed by the symmetry debate. The asymmetry perspective would suggest supporters of far-left Democratic candidates should differ from supporters of moderates, who would in turn differ from Trump supporters. In contrast, the symmetry perspective would suggest that supporters of moderate candidates should differ from both supporters of Trump and relatively extreme Democratic candidates, who should both show psychological similarities to each other. Below, we further detail these predictions, the rationale behind them, and how the 2020 primaries allowed us to test these predictions in a unique way.

\section{Political Ideology and The Symmetry Debate}

Conservatism is commonly defined along two dimensions: Resistance to change, and opposition to equality (Jost, 2006). Liberalism is defined by the opposite end of these spectrums (preference for change and equality). According to the Theory of Conservatism as Motivated Social Cognition (Jost et al., 2003), people with enhanced sensitivity to threat and uncertainty in the environment are predisposed to epistemic, existential, and relational motives. These social-cognitive motives produce behaviors to reduce uncertainty, defend the existential self, and share reality with others, leading to the rationalization of self-interest and the status quo. These, in turn, predispose individuals to endorsing political conservatism. According to such perspectives, the correlates of conservatism are asymmetrical, showing a linear relationship across the political spectrum. For example, the asymmetry perspective holds that openness to experience is negatively associated with conservatism (a prediction that is empirically supported, Carney, Jost, Gosling, \& Potter, 2008).

Alternatively, the ideological extremity hypothesis (i.e., symmetry perspective; see Greenberg \& Jonas, 2003) predicts curvilinear patterns, with extremity of belief (rather than its content) being associated with similar characteristics. From 
this perspective, for example, openness to experience should be negatively associated with ideological extremity such that those at either extreme should be lower on this construct than those who are moderate (forming an inverted U-shaped curve across the political spectrum).

Much research in political psychology has shown support for the asymmetry perspective (see Jost, 2017 for a review) although some recent research has also demonstrated support for the symmetry perspective (reviewed below). Notably, important methodological differences characterize research supporting these two perspectives. Research supporting asymmetry has relied on correlational methodology and measures of personality characteristics (e.g., Zmigrod, Rentfrow, \& Robbins, 2020). In contrast, most of the research supporting the symmetry perspective is experimental. In our view, these two perspectives may not be entirely mutually exclusive. From a personality psychology perspective, theories such as motivated social cognition may explain psychological antecedents and outcomes of right-wing ideology. From a social psychology perspective, it is possible that, despite these dispositional differences, liberals behave in similar ways to conservatives depending on context.

The present research advances this debate by offering a complementary methodological approach to studying these issues: Testing for asymmetries vs. symmetries as a function of voter preferences. Because a great deal of research addressing the symmetry debate has considered cognitive and interpersonal variables as correlates of political ideology, we focused on these two types of variables. We next briefly review the contemporary scientific understanding of these relationships from each perspective.

\section{Cognitive Asymmetry vs. Symmetry}

Accumulated empirical research, spanning over 70 years, supports the asymmetrical rigidity of the right hypothesis (Adorno et al., 1950/1982; Jost, Sterling, \& Stern, 2018; Tetlock, 1983; see Jost, 2017 for a review) that right-wing ideology is associated uniquely with constructs reflecting cognitive rigidity. For instance, conservatism is related negatively to openness to experience (Carney, Jost, Gosling, \& Potter, 2008) and active open-minded thinking (Yilmaz \& Saribay, 2017) and positively related to dogmatism (Choma et al., 2012), need for cognitive closure (Kruglanski \& Webster, 1996), intolerance of ambiguity (Van Hiel, Onraet, \& De Pauw, 2010), and personal need for structure (Altemeyer, 1998), and these differences may have biological underpinnings (Hibbing, Smith, \& Alford, 2013).

From the symmetry perspective, we would expect that extremity (rather than content) of political views accounts for differences in cognitive style. Some research supports this view. For instance, extreme liberals and extreme conservatives engage in similar levels of motivated reasoning to defend their pre-existing views (Ditto et al., 2019; Gampa et al., 2019) and similarly may avoid exposure to dissenting opinions (Frimer et al., 2017; although this may not be the case on Twitter, where liberals are more likely to share ideologically incongruent information, Barberá, Jost, Nagler, Tucker, \& Bonneau, 2015). Likewise, some research suggests that the low integrative complexity typically associated with conservatism is, in fact, domain specific (Conway et al., 2016), and that liberals and conservatives engage in equal amounts of motivated disbelief depending on the topic (Campbell \& Kay, 2014). Those with extreme political identities show greater cognitive inflexibility (Zmigrod et al., 2020) and both extreme liberals and conservatives show lower metacognitive awareness (Rollwage et al., 2018).

In the current study, we assessed openness to experience, active open-minded thinking, dogmatism, and preference for one right answer as measures of cognitive style. We tested competing predictions informed by the asymmetry and symmetry hypotheses by examining these constructs among supporters of leftist (Sanders/Warren), moderate (Biden/Bloomberg) and right-wing (Trump) candidates in the 2020 primaries.

\section{Interpersonal Asymmetry vs. Symmetry}

From the asymmetry perspective, interpersonal empathy and warmth likely share a negative linear relationship with conservatism. Research shows that liberalism is associated positively with constructs reflecting interpersonal warmth. For example, focusing on the Five Factor Model of personality, political ideology shares a nuanced relationship with agreeableness. Conservatism is positively associated with the facet of agreeableness that involves politeness and conformity while liberalism is positively associated with the facet of agreeableness reflecting compassion and kindness 
(Hirsh, DeYoung, Xu, \& Peterson, 2010). Likewise, liberals tend to experience greater motivation to empathize and are more successful at empathizing with others than conservatives (Hasson, Tamir, Brahms, Cohrs, \& Halperin, 2018).

Although most existing research in the interpersonal domain supports the asymmetry side of the debate, some research does suggest symmetry. For example, liberals and conservatives similarly dislike each other (Toner et al., 2013). Liberals and conservatives also show similar levels of bias against ideologically dissimilar others (e.g., Crawford et al., 2017). However, an important caveat in interpreting these findings through the lens of symmetry is that such symmetry appears to be limited to the ideological domain. Right-wing ideology is uniquely associated with various forms of hostility to dissimilar others or prejudice (Onraet et al., 2015), including racism (Brandt \& Reyna, 2014), sexism (Sibley et al., 2007), homophobia (Crawford et al., 2016; Stefurak et al., 2010), and xenophobia (Thomsen et al., 2008; Weise et al., 2012); and no research has demonstrated curvilinear relationships between political ideology and these variables. Instead, research supporting symmetry for interpersonal variables is experimental and typically operationalizes prejudice as ratings of warmth towards ideologically similar vs. dissimilar targets. Although these studies tend to show similar patterns among liberals and conservatives, with each indicating cold feelings towards ideologically dissimilar targets, differences tend to be more pronounced among conservatives than liberals (reflecting a J rather than $U$ shaped curve ${ }^{1}$ ). When dispositional measures of prejudice are included in these studies, conservatism remains positively related to them.

In the present study, we measured compassion and empathy to test whether these broad dispositional interpersonal orientations towards others showed asymmetrical or symmetrical patterns for supporters of candidates across the political spectrum. Because we view the evidence reviewed above as stronger for cognitive (vs. interpersonal) symmetry, we expected that if evidence supporting symmetry were observed, it would be more likely for the cognitive domain (openness, active open minded thinking, dogmatism, preference for one right answer) than the interpersonal domain. Further, because evidence of interpersonal symmetry is somewhat less compelling, particularly due to the methodological issues highlighted above, we expected to observe asymmetrical patterns for compassion and empathy across supporters of relatively liberal vs. moderate vs. conservative candidates. ${ }^{2}$

\section{Asymmetry vs. Symmetry in the 2020 Primaries}

The current research was designed to contribute to the symmetry debate in a unique way. We tested competing predictions informed by the symmetry and asymmetry perspectives using correlational methodology and personality measures in the context of a real-world behavior, voting. Specifically, rather than test for linear vs. curvilinear relationships between measures of political ideology and psychological characteristics, we tested for mean-level differences on psychological characteristics among voters favoring relatively liberal vs. conservative candidates (asymmetry) and supporters of ideological extreme vs. moderate candidates (symmetry). This approach allowed us to examine whether psychological variables associated with support for conservative, liberal, and ideologically extreme candidates showed patterns more consistent with the asymmetry or symmetry hypothesis.

\footnotetext{
1) For example, Chambers, Schlenker, and Collisson (2013) argue they find evidence of symmetrical outgroup prejudice among liberals and conservatives. The evidence supporting this prediction is that 170 liberals and conservatives (operationalized as scores above vs. below midpoint on a single-item measure of political ideology) show greater warmth (on a feeling thermometer) towards targets who share their own ideology, compared to those who do not. However, the magnitude of the difference between evaluations of in-group vs. out-group targets among liberal and conservative participants is striking (almost 3 times stronger for conservatives). For conservative participants, the difference between warm ingroup evaluations, $M(S D)=3.86(0.48)$ and cold outgroup evaluations, $M(S D)=2.57(0.65)$ was 1.29 . For liberals, it was 0.49 , ingroup $M(S D)=3.48(0.58)$ vs. outgroup $M(S D)=2.99(0.66)$. This pattern indicates more of a J than $\mathrm{U}$ shaped curve. The same pattern is present in all 3 original studies, including data from ANES. Additionally, conservatism measures were positively and strongly related to different measures of racism in all 3 studies.

2) In this study, we also included an ideological category of variables. These included measures of economic system justification and anomie. Because these have not generally been the focus of the asymmetry vs. symmetry debate, in line with a reviewer recommendation, we present full results in the Supplementary Materials (pp. 3-11). To summarize briefly, Sanders and Warren supporters were lower on economic system justification than Biden and Bloomberg supporters. Supporters of all Democrats were lower than Trump supporters. Anomie is broken down into two facets: Breakdown of social fabric, and breakdown of leadership. Supporters of Sanders and Warren were relatively high on the belief in the breakdown of social fabric, and unlike supporters of moderates, did not differ from Trump supporters on this construct (implicating symmetry). Results for breakdown of leadership showed a linear pattern with supporters of Sanders being highest, and supporters of Trump being lowest.
} 
In the Democratic primary, Sanders and Warren represented the far left (and campaigned on positions that were atypically liberal among Democratic candidates in the U.S.; Martin, 2019). Relative to Sanders and Warren, Biden was closer to the center, and Bloomberg was perhaps the most moderate or centrist (Detrow, 2019). Examining mean-level scores on the variables of interest among supporters of these candidates provided a way to examine whether constructs associated with liberalism change linearly as the candidate supported was further left, or if, instead, we might see similarities on the extremes of political views and differences between extremists and moderates (the symmetry view suggesting curvilinearity).

As an example, the asymmetry perspective suggests that dogmatism should have a positive and linear relationship with conservatism (Choma et al., 2012). Thus, in the context of the 2020 primaries, dogmatism should be highest among Trump supporters, lower among more moderate Biden/Bloomberg supporters, and lowest among relatively liberal Sanders/Warren supporters. In contrast, the symmetry perspective suggests dogmatism should have a curvilinear relationship with conservatism such that it is highest both among those who are the most conservative and the most liberal. Thus, in the 2020 primaries, dogmatism should be similarly high among Trump supporters as well as supporters of Sanders/Warren, and should be lowest among moderates (supporters of Biden/Bloomberg).

Before presenting the study, we note that the placement of candidates along the political spectrum is not always straightforward, especially at the far-left end. Sanders and Warren both were relatively progressive in the Democratic field. Warren's proposed policies, voting record, and positions on issues such as immigration, climate, healthcare and economic justice qualified her as the most liberal candidate (Detrow, 2019), according to an analysis by a political grass-roots organization (Phelps, 2019). Although Warren may well have been the most liberal candidate from these objective indicators, a nationally representative survey of more than 40,000 voters showed that Sanders was perceived as the most liberal candidate (followed sequentially by Warren, Biden, Bloomberg, then Trump, see Broockman \& Kalla, 2020 , pp. 7-8). In our presentation of the results of our analyses, we place Sanders at the far-left end of the political spectrum.

Similarly, due to the realities of the 2020 primary, Donald J. Trump was the only conservative candidate included in these analyses. Whether Trump represents conservatism per se, is less important to this study than that he was, certainly, more conservative than the democratic field. Note, as well, that, like the decision to place Sanders to the left of Warren, this decision is inconsequential with regard to the conclusions we might draw. Because we focus on mean differences across candidate supporters, any differences between Warren and Sanders supporters or among the supporters of democratic candidates can certainly exist apart from their differences with Trump. Any such differences can still be interpreted through the lens of asymmetry vs. symmetry.

\section{Overview and Predictions}

After Super Tuesday, 2020, participants indicated the candidate they supported in the primaries and completed measures of cognitive and interpersonal characteristics. Below we summarize the pre-registered predictions (Supplementary Materials):

The competing hypotheses tested in this study are illustrated in Figure 1. According to the asymmetry hypothesis (top panel Figure 1), supporters of leftist candidates (Sanders/Warren) should be lowest on cognitive rigidity (high openness to experience, high active open minded thinking, lower on dogmatism and low preference for one right answer), and highest on interpersonal warmth (high compassion, and high empathy). Supporters of centrist candidates (Biden/Bloomberg), should in turn also be lower on cognitive rigidity, and higher on interpersonal warmth than Trump supporters. The symmetry hypothesis (bottom panel Figure 1) suggests the same pattern for centrists (Biden/Bloomberg) vs. Trump supporters, but the opposite pattern for leftists (Sanders/Warren) vs. centrists (Biden/Bloomberg). Specifically, according to this perspective, Biden and Bloomberg supporters should be lower on cognitive rigidity and higher on interpersonal warmth than Sanders and Warren supporters. Additionally, Sanders, Warren and Trump supporters should show similar levels on variables reflecting cognitive rigidity and interpersonal warmth. 


\section{Figure 1}

Hypothetical Results Supporting Asymmetry (top panel) vs. Symmetry (bottom panel) for Cognitive Flexibility and Interpersonal Warmth Across the Candidate Spectrum
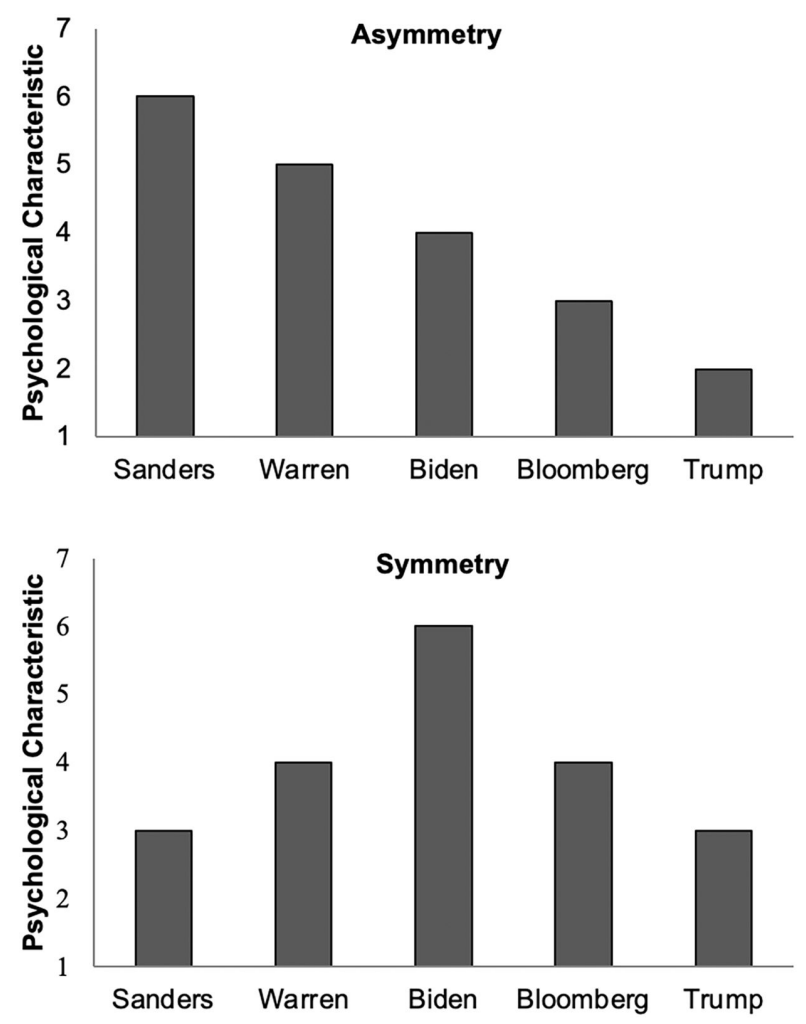

\section{Method}

\section{Participants}

We recruited 831 participants in an online study conducted on Cloud Research on March 3, 2020, following Super Tuesday, when many U.S. states hold primary elections. The candidate holding the lead after Super Tuesday often secures the eventual nomination. At this point in the primary season, many Americans had voted for a candidate, and the race was salient due to widespread media coverage. Because Super Tuesday occurred before the primary season ended, Americans from some states had not yet voted for a primary candidate. However, the timing of Super Tuesday was advantageous for our purposes because a broad spectrum of Democratic candidates remained in the race.

The sample we collected was 45.2\% women, 59.6\% White/European American, 28.5\% Black/African American, 5.7\% Latinx, 3.8\% Asian American, 1.0\% Native American, and 1.4\% indicated "other." Age, $M(S D)=28.19$ (11.90) ranged from 19 to 75. Modal education was a Bachelors. Median income was $\$ 50,001-\$ 75,000$. This sample was younger, more educated, and more racially diverse than national Democrat and Republican voters (see Supplementary Materials, p. 19). Although this was not a nationally representative sample, research using this platform during the 2016 Presidential Election showed the same pattern of results as nationally representative data during that period (see Womick et al., 2019). Because this study was focused on understanding relationships between constructs (how cognitive rigidity and interpersonal warmth relate to liberalism), rather than accurately predicting an election outcome, national representativeness was a less important methodological consideration than theoretical relevance and strong measurement (Mook, 1983). 


\section{Measures}

All measures, data, code, and the data analysis plan can be found at the link for the pre-registration.

\section{Cognitive}

We measured cognitive dispositions associated with conservatism and liberalism. For openness to experience, we administered 48 items from the NEO-PI-R (Costa \& McCrae, 1992), $M(S D)=4.49(0.72), \alpha=.91$. We measured active open-minded thinking with The Actively Open-Minded Thinking Scale (Haran, Ritov, \& Mellers, 2013; "Allowing oneself to be convinced by an opposing argument is a sign of good character), $M(S D)=4.73(1.20), \alpha=.64$. Dogmatism was measured using 7 items from Altemeyer's (2002) DOG scale (e.g., "Flexibility in thinking is another name for being wishy-washy"), $M(S D)=3.06(0.90), \alpha=.64$.

We measured the preference for one right answer using items pooled from measures of intolerance of ambiguity (Stanley Budner, 1962; 2 items: “An expert who doesn't come up with a definite answer probably doesn't know too much," "The sooner we all acquire similar values and ideals, the better"); the Social Conformity vs. Autonomy Scale (Feldman, 2003; "If we cannot achieve agreement on our values, we will never be able to keep this society together"), and the Epistemic Belief Inventory- Certain Knowledge (Schraw et al., 2002; "If two people are arguing about something, at least one of them must be wrong"); in addition to three face valid items created for the purposes of measuring this construct ("There is usually one right answer to problems; I tend to prefer having one right answer, rather than valuing a variety of approaches to an issue; I believe there is usually one right way of doing things"). Thus, 7 items tapped preference for one right answer, $M(S D)=4.20(1.54), \alpha=.93$.

\section{Interpersonal}

We included two measures of interpersonal orientation, the 16-item Compassion Scale (Pommier, Neff, \& Tóth-Király, 2020; e.g., "I like to be there for others in times of difficulty), $M(S D)=5.30(0.87), \alpha=.87$; and the 16-item Toronto Empathy Questionnaire (Spreng, McKinnon, Mar, \& Levine, 2009; e.g., "It upsets me to see someone being treated disrespectfully"), $M(S D)=4.93$ (1.09), $\alpha=.90$.

Finally, participants were asked whether they planned to vote for President Trump $(n=425)$, or participate in the Democratic Primary. If participants indicated they would participate in the Democratic Primary (or had already done so), they were asked for whom they intended to vote (or for whom they had voted). Options included Elizabeth Warren $(n=50)$, Bernie Sanders $(n=172)$, Amy Klobuchar $(n=8)$, Pete Buttigieg $(n=10)$, Michael Bloomberg $(n=$ $42)$, Joe Biden $(n=91)$, and "other" $(n=5)$. Because Klobuchar and Buttigieg ultimately endorsed Biden, we collapsed supporters of all three candidates, who will be presented subsequently as Biden supporters $(n=109)$ (note, we conducted post-hoc robustness checks, and results were the same regardless of whether Klobuchar and Buttigieg were included, see Supplementary Materials, Table S8, pp. 20-21). Participants who did not select a candidate or indicated they would not vote were excluded from multivariate analyses $(n=42)$.

\section{Results}

See the Supplementary Materials (Table S1, p. 2) for correlations among measures. We created a categorical variable with 5 levels, reflecting support for each candidate (Sanders, Warren, Biden, Bloomberg, Trump) ranging from most liberal to most conservative.

To test our predictions, we submitted all variables to a general linear model using the candidate preference as the independent variable (bootstrapped with 1000 resamplings), controlling for gender, ethnicity, age, education, and income. This model allowed us to estimate the mean (adjusted for demographic factors) for each group of candidate supporters, and examine Bonferroni corrected comparisons across supporters of each candidate, on each variable. Table 1 shows the results. ${ }^{3}$ 
Table 1

Means for Supporters of Each Candidates on Each Variable

\begin{tabular}{|c|c|c|c|c|c|c|c|}
\hline & & Openness & AOT & Dogmatism & One Right Answer & Compassion & Empathy \\
\hline Candidate & $n$ & $\begin{array}{c}M(S D) \\
{[95 \% \mathrm{CI}]}\end{array}$ & $\begin{array}{c}M(S D) \\
{[95 \% \mathrm{CI}]}\end{array}$ & $\begin{array}{c}M(S D) \\
{[95 \% \mathrm{CI}]}\end{array}$ & $\begin{array}{c}M(S D) \\
{[95 \% \mathrm{CI}]}\end{array}$ & $\begin{array}{c}M(S D) \\
{[95 \% \mathrm{CI}]}\end{array}$ & $\begin{array}{c}M(S D) \\
{[95 \% \mathrm{CI}]}\end{array}$ \\
\hline Trump & 384 & $\begin{array}{r}4.30(0.51) \\
{[4.24,4.36]_{\mathrm{a}}}\end{array}$ & $\begin{array}{r}4.37(0.94) \\
{[4.27,4.46]_{\mathrm{a}}}\end{array}$ & $\begin{array}{r}3.21(0.69) \\
{[3.13,3.29]_{\mathrm{a}}}\end{array}$ & $\begin{array}{r}4.80(1.33) \\
{[4.58,4.82]_{\mathrm{a}}}\end{array}$ & $\begin{array}{r}5.18(0.75) \\
{[5.11,5.27]_{\mathrm{a}}}\end{array}$ & $\begin{array}{r}4.70(0.97) \\
{[4.60,4.81]_{\mathrm{a}}}\end{array}$ \\
\hline Bloomberg & 37 & $\begin{array}{c}4.43(0.65) \\
{[4.23,4.61]_{\mathrm{ab}}}\end{array}$ & $\begin{array}{c}4.70(1.12) \\
{[4.40,4.99]_{\mathrm{ab}}}\end{array}$ & $\begin{array}{r}3.28(0.81) \\
{[3.03,3.53]_{\mathrm{a}}}\end{array}$ & $\begin{array}{r}3.88(1.40) \\
{[3.49,4.31]_{b}}\end{array}$ & $\begin{array}{c}5.19(0.94) \\
{[4.92,5.47]_{\mathrm{ab}}}\end{array}$ & $\begin{array}{c}4.97(1.00) \\
{[4.70,5.23]_{\mathrm{ab}}}\end{array}$ \\
\hline Biden & 94 & $\begin{array}{c}4.64(0.74) \\
{[4.50,4.78]_{\mathrm{bc}}}\end{array}$ & $\begin{array}{c}5.00(1.11) \\
{[4.82,5.20]_{\mathrm{bc}}}\end{array}$ & $\begin{array}{r}2.84(0.92) \\
{[2.68,3.03]_{b}}\end{array}$ & $\begin{array}{r}3.81(1.41) \\
{[3.56,4.07]_{b}}\end{array}$ & $\begin{array}{r}5.45(0.87) \\
{[5.28,5.61]_{\mathrm{b}}}\end{array}$ & $\begin{array}{r}5.16(1.08) \\
{[4.97,5.35]_{b}}\end{array}$ \\
\hline Warren & 43 & $\begin{array}{r}4.82(0.69) \\
{[4.63,5.02]_{c}}\end{array}$ & $\begin{array}{r}5.42(0.95) \\
{[5.14,5.70]_{c}}\end{array}$ & $\begin{array}{r}2.70(0.92) \\
{[2.44,2.97]_{b}}\end{array}$ & $\begin{array}{r}3.56(1.30) \\
{[3.16,3.96]_{b}}\end{array}$ & $\begin{array}{r}5.47(0.86) \\
{[5.21,5.72]_{\mathrm{b}}}\end{array}$ & $\begin{array}{r}5.23(1.02) \\
{[4.89,5.55]_{\mathrm{b}}}\end{array}$ \\
\hline Sanders & 147 & $\begin{array}{r}4.79(0.83) \\
{[4.65,4.92]_{\mathrm{c}}}\end{array}$ & $\begin{array}{c}5.13(1.21) \\
{[4.98,5.29]_{\mathrm{bc}}}\end{array}$ & $\begin{array}{r}2.80(0.96) \\
{[2.66,2.95]_{b}}\end{array}$ & $\begin{array}{r}3.79(1.32) \\
{[3.56,4.03]_{b}}\end{array}$ & $\begin{array}{r}5.49(0.96) \\
{[5.33,5.64]_{\mathrm{b}}}\end{array}$ & $\begin{array}{r}5.26(1.09) \\
{[5.08,5.47]_{b}}\end{array}$ \\
\hline
\end{tabular}

Note. Undecided voters were not included in these analyses. Values were bootstrapped with 1000 resamplings. All values were adjusted for gender, ethnicity, age, education, and income. Candidates in the same column with differing subscripts significantly differed on the variable (Bonferroni corrected), $p$ 's ranged from <.03 to .001 (except for Warren vs. Trump supporters on compassion, $p=.036$ ). Openness $=$ Openness to Experience; AOT = Active Open Minded Thinking; DOG = Dogmatism. All omnibus $F$ tests were significant, all $p$ 's $<.001$.

\section{Cognitive Variables}

\section{Openness to Experience}

Trump supporters were lower on openness than supporters of all Democrats (all p's =.001), except Bloomberg supporters. Sanders and Warren supporters were significantly higher on openness to experience than Bloomberg supporters ( $p$ 's $=.005$ and .011 , respectively), and did not differ from Biden supporters or each other. Biden supporters did not differ from other Democrat supporters. Thus, as shown in the top panel of Figure 2, Democratic candidates were uniformly higher on openness to experience than Trump supporters (with the exception of Bloomberg), consistent with the asymmetry perspective. Those on the left were highest on this variable, and those on the right were lowest.

\section{Active Open-Minded Thinking}

Warren supporters were highest on active-open minded thinking, significantly differing from Trump $(p=.001)$, Bloomberg $(p=.002)$, and Biden supporters $(p=.028)$. They did not differ significantly from Sanders supporters (despite a relatively large mean difference). Sanders supporters were significantly higher on active open-minded thinking than Trump supporters, and Bloomberg supporters ( $p$ 's $=.001$ and .016 , respectively), and did not differ from the other candidates. Biden supporters were higher than Trump supporters $(p=.001)$, but did not differ from Bloomberg supporters. Bloomberg supporters did not differ from Trump supporters $(p=.042)$.

As the bottom panel of Figure 2 shows, the patterns of means might suggest symmetry for active-open minded thinking. Means increased from the right-wing (Trump supporters) to the left-wing (Warren supporters), then on the far left, dipped among Sanders supporters. Bearing in mind that our placement of Sanders to the left of Warren is debatable, the pattern might be viewed as a weak J-shaped curve across the right-left continuum.

3) When the results of this model indicated a variable to be uniquely associated with support for a given Democratic candidate relative to other Democrats, we followed-up with logistic regression, regressing support for that candidate (vs. other Democrats) on the variable of interest, controlling for demographics and the other target variables. Interested readers can find these follow-up analyses in the Supplementary Materials (pp. 12-17). 


\section{Figure 2}

Candidate Means on Openness to Experience (top panel) and Active Open-Minded Thinking
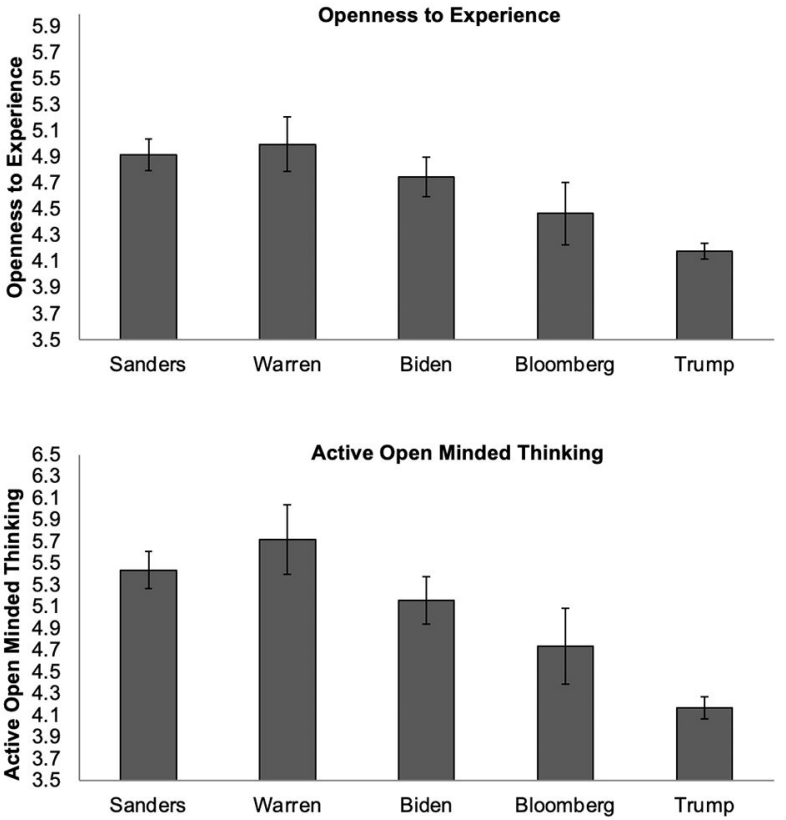

\section{Dogmatism}

Sanders, Warren, and Biden supporters were significantly lower on dogmatism than Bloomberg (all p's <.008) and Trump supporters (all p's $<.002$ ), and did not differ from each other. Bloomberg and Trump supporters did not differ from each other. The patterns of means shown in Figure 3 (top panel) strongly support asymmetry for dogmatism.

\section{Figure 3}

Means for Dogmatism (top panel) and Preference for One Right Answer (bottom panel) Across the Candidate Spectrum
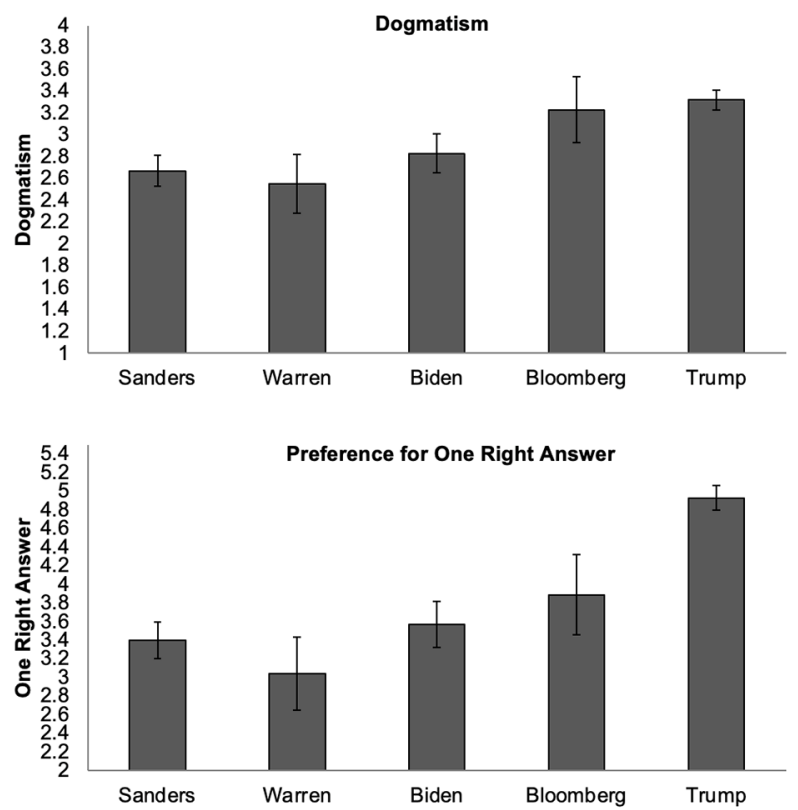


\section{One Right Answer}

Trump supporters were significantly higher on preference for one right answer than supporters of all Democratic candidates (all p's $=.001$ ), who did not differ from each other. Although differences were not significant, supporters of Democrat candidates showed a similar pattern to that for active open-minded thinking. Figure 3 (bottom panel) shows that the means on this variable trended downward across the candidates before increasing again among Sanders supporters, leaving leave open the possibility of symmetry.

\section{Interpersonal Variables}

\section{Compassion}

Trump supporters were lower on compassion than supporters of all Democratic candidates ( $p$ 's ranged from .002 vs. Sanders to .038 vs. Warren), except Bloomberg. Supporters of Democratic candidates did not differ from each other on compassion. This pattern, shown in Figure 4 (top panel), supports the asymmetry hypothesis.

\section{Figure 4}

Means for Supporters of Each Candidate on Compassion (top panel) and Empathy (bottom panel)
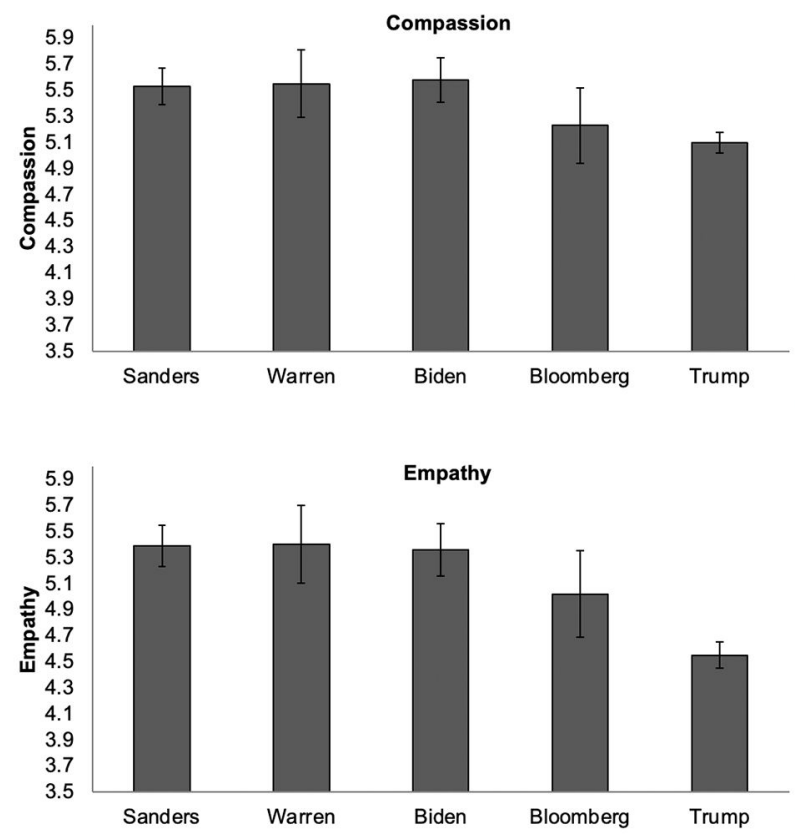

\section{Empathy}

Empathy was significantly higher among supporters of all Democratic candidates (excluding Bloomberg) than among Trump supporters ( $p$ 's ranged from .001 for Sanders to .036 for Warren). Bloomberg supporters did not differ from Trump supporters. Democratic candidate supporters did not differ from each other. As Figure 4 (bottom panel) shows, means showed an ascending pattern from the right to left, supporting the asymmetry perspective.

\section{Discussion}

The current research examined psychological variables underpinning political ideology as a function of candidate support in the 2020 Presidential Primaries. We tested competing predictions informed by the asymmetry and symmetry hypotheses. Patterns of significance and means across the candidate spectrum generally supported the asymmetry 
hypothesis. Although no significant effects emerged in support of the symmetry perspective, in the cases of active open-minded thinking and the preference for one right answer, the patterns across the candidate spectrum may hint at the possibility of symmetrical relationships.

\section{Conservatism and The Symmetry vs. Asymmetry Debate}

The present results largely support asymmetrical theories of ideology, particularly the Theory of Conservatism as Motivated Social Cognition (Jost et al., 2003). Consistent with past research (e.g., Altemeyer, 1998; Carney, Jost, Gosling, \& Potter, 2008; Choma et al., 2012; Kruglanski \& Webster, 1996; Van Hiel, Onraet, \& De Pauw, 2010; Yilmaz \& Saribay, 2017), openness to experience, active open-minded thinking, (low) dogmatism, (low) preference for one right answer, compassion, and empathy were higher among supporters of liberal candidates, and lower among Trump supporters. Future research might use correlational and experimental methodology to test whether symmetries across the political spectrum are stronger for some categories of variables (e.g., cognitive dispositions) than they are for others (e.g., interpersonal orientation).

Certainly, the strong support for asymmetry (and lack for support for symmetry) on interpersonal constructs highlights the issue noted previously with regard to operationalizing interpersonal variables. Specifically, research supporting interpersonal symmetry has shown only that extreme liberals and conservatives are similarly cold towards ideologically dissimilar others (e.g., Crawford et al., 2017). At the same time, research has demonstrated repeatedly that conservatism is positively associated with validated measures of intolerance-ranging from racism to homophobia-and no curvilinear relationship between these variables and ideology that would support the symmetry hypothesis (e.g. Sibley, Wilson, \& Duckitt, 2007; Weise et al., 2012). The present study adds to this body of evidence by showing that personality traits indicating interpersonal warmth--compassion and empathy-likewise show no symmetrical pattern among moderate vs. relatively extreme liberal and conservative voters.

Overall, this study failed to provide support for the symmetry hypothesis, however the pattern of means for cognitive variables may hint at the possibility of symmetry. Active open-minded thinking most strongly demonstrated this pattern, but the trends for openness to experience, dogmatism, and preference for one right answer were similar. These variables showed patterns similar to a weak J-shaped (or inverted J) curve across the candidate spectrum. Such a possibility would be consistent with the relatively stronger support for cognitive (e.g., Ditto et al., 2019) rather than interpersonal symmetries (e.g., Crawford et al., 2017) in previous research.

\section{Liberalism}

Political psychological research has almost exclusively focused on understanding conservatism as a problem over the last 70 years, viewing psychology as the solution to it (e.g., Adorno et al., 1950/1982). In this tradition, liberalism is typically operationalized as low scores on measures of conservatism. It is theoretically unclear if liberal ideology results from low levels of epistemic, existential and relational needs that produce conservative ideology, or if instead there may be other relevant needs that primarily drive liberalism. Past research has shown that comparing Republican primary voters in 2016 revealed unique correlates of support for Donald J. Trump (Womick et al., 2019). Might comparing cognitive and interpersonal variables across supporters of various candidates in the 2020 Democratic primary might help to illuminate potential differences among liberals? The present results suggest the answer to this question is, no. Indeed, in the present study, few variables distinguished supporters of different Democratic candidates from each other. One exception was that active open-minded thinking was uniquely high among supports of Warren, compared to other Democratic candidates.

Although supporters of Bloomberg did not significantly differ from supporters of other Democrats on these constructs, mean estimates for this group often looked more similar to Trump supporters than supporters of other Democrats. These results may suggest Bloomberg supporters were more similar to mainstream conservatives than liberals, consistent with evaluations by policy experts and everyday Americans of Bloomberg as the most conservative candidate among Democrats (Broockman \& Kalla, 2020; Detrow, 2019; Phelps, 2019). These patterns likely occurred due to several factors, including the absence of competitors in the Republican primaries, the lack of certainty regarding a frontrunner among Democratic primary candidates, and some similarities between Bloomberg and Trump as wealthy 
businessmen. We otherwise failed to identify unique constructs distinguishing supporters of different Democratic candidates occupying different stances across the liberal spectrum.

The lack of differences among supporters of Democratic candidates is consistent with research operationalizing liberalism as low scores on conservatism (rather than as a distinguishable but non-orthogonal construct, e.g., Choma et al., 2012). In other words, supporters of Democratic candidates appear to inhabit the opposite pole of the spectrum from supporters of Republicans, not just on political ideology, but on interpersonal warmth, and cognitive rigidity. In particular, interpersonal warmth (compassion and empathy) was unexpectedly uniform across supporters of Democratic candidates. Variables tapping interpersonal orientations may be definitional of liberalism broadly, and may not be useful to understanding moderate vs. extreme liberalism.

One implication of the present study is that the search for symmetry in interpersonal dimensions does not appear to be a fruitful direction for future research. Certainly, if research continues to pursue this direction, it is important to theoretically specify why symmetry is observed only for ratings of warmth vs. coldness of ideologically dissimilar others, and not general interpersonal hostility or warmth. Our findings with regard to interpersonal variables are consistent with the asymmetrical link between conservatism and prejudice.

With regard to cognitive variables, although patterns across the candidate spectrum were not statistically significant, these were not as uniform as those for interpersonal variables. It is possible that with larger sample sizes, these mean differences would have reached statistical significance. Continuing to consider differences in cognitive dispositions (as well as other yet-to-be specified constructs) among supporters of relatively moderate vs. extreme liberal candidates in the future may help us understand support for Democratic candidates in the U.S., the nature of liberalism, and the meaning of ideological extremity. These results also suggest that if symmetries across the political spectrum exist, they are more likely to be observed for cognitive rather than interpersonal dispositions. Taken together, these results allow for the possibility that interpersonal warmth may distinguish left vs. right ideology, and cognitive variables may distinguish moderate vs. extreme ideology.

\section{Limitations}

An important consideration in interpreting the present results is restriction of range for liberalism. The Republican party is relatively conservative compared to other right-wing parties around the world (Norris, 2020). The U.S. Democratic party is arguably moderate compared to other liberal parties globally (Norris, 2020). While Sanders and Warren ran on revolutionary platforms for U.S. politics (Martin, 2019), their views would not be considered so progressive in other cultural contexts. Ultimately, these differences point to the possibility of a restriction of range on the left-wing of the political spectrum in the U.S. Thus, it may be fruitful for future research testing symmetries across the political spectrum to focus on cultural contexts outside of U.S. politics. Symmetries (particularly cognitive ones) may be more likely in more liberal cultures, as others have noted previously (see Jost et al., 2003, pp. 342-343).

Similarly, relative to other fields, political psychology is subject to history effects. Certainly, the idiosyncratic candidates in this study may present one such effect. The most extremely liberal candidates who ran in the 2020 primary may not have been as ideologically extreme as the most extreme conservative candidate (potentially reflecting the restriction of range issue detailed above). This feature of the primaries may have limited our ability to find support for the symmetry hypothesis.

Trump was an atypical candidate. Likewise, his supporters are atypical in psychologically meaningful ways. Specifically, when compared to supporters of 2016 Democrats, Trump supporters showed higher social dominance orientation and right-wing authoritarianism (e.g., Azevedo, Jost, \& Rothmund, 2017; Choma \& Hanoch, 2017; Ludeke, Klitgaard, \& Vitriol, 2018), a pattern observed in every Presidential election since 1964 (Jost, West, \& Gosling, 2009, pp. 105-106). However, when compared to supporters of other 2016 Republican candidates, Trump supporters differed only on group-based dominance and authoritarian aggression, and did not differ from them on anti-egalitarianism, authoritarian submission, or authoritarian conventionalism (Womick et al., 2019). Thus, Trump supporters systematically differ from supporters of other Republicans, but they are not qualitatively different. Notably, many supporters of other Republicans in 2016 likely transitioned to Trump support once he won the nomination, and may be included in the current sample of Trump supporters. Thus, we do not believe Trump's atypicality dramatically affected the current results. 
More broadly, an important consideration is that even if Trump supporters are atypical for conservatives in the U.S., the asymmetry and symmetry hypotheses make essentially the same predictions for conservatism. As shown in Figure 1, the main focus of this debate has been whether or not our understanding of extreme liberalism needs to be revised. For instance, existing work has not focused on showing extreme conservatives are similarly non-prejudiced/non-dogmatic as extreme liberals, but instead that extreme liberals are similarly intolerant of ideological dissimilarity / dogmatic as extreme conservatives (e.g., Crawford et al., 2017; Ditto et al., 2019). Thus, comparisons of supporters of moderate Democrat candidates to relatively extreme Democrat candidates speak most directly to this debate.

One final limitation on the inferences that can be drawn from the present results is that the data were not nationally representative, as is evidenced by the fact that our sample showed highest support for Bernie Sanders compared to the rest of the Democratic candidates (inconsistent with the eventual outcome of the primary). However, as the central focus of this study was not the psychological factors that would predict the winner of the election, but understanding how cognitive and interpersonal dispositions predict support for candidates across the left-wing of the political spectrum, we view the large number of Sanders and Warren supporters in these data as a strength.

In light of the above considerations, it is crucial that evidence provided by this study is considered as making an initial but by no means definitive contribution to the mounting literature on the symmetry vs. asymmetry debate. Future researchers might take advantage of primaries (and local elections with a range of candidates in each party) to test similar predictions (ultimately using meta-analytic approaches to synthesize and evaluate these as a whole). Only with substantial rigorous evidence, considered over many elections, occurring over time, and including appropriate measures can a clear view of the psychological variables underpinning support for relatively extreme vs. moderate candidates be brought into focus. The current study represents one step in that direction.

\section{Conclusion}

We tested competing predictions informed by the asymmetry and symmetry hypotheses in the context of the 2020 U.S. Presidential Primaries. Results more strongly supported the asymmetry hypothesis: Supporters of Democratic candidates were lower on cognitive rigidity and higher on interpersonal warmth than Trump supporters. Additionally, supporters of Democrats did not differ from each other on these constructs in a manner that would support the symmetry hypothesis. However, these data open the possibility that extreme ideology may be characterized by cognitive rigidity, and left-right differences may be characterized by differences in interpersonal orientation.

Funding: The authors have no funding to report.

Acknowledgments: The authors have no support to report.

Competing Interests: The authors have declared that no competing interests exist.

Data Availability: For this article, a dataset is freely available (Womick \& King, 2021a).

\section{Supplementary Materials}

The Supplementary Materials contain the following items (for access see Index of Supplementary Materials below):

- Via the Open Science Framework (OSF) repository: The preregistration protocol, all measures, data, code, and the data analysis plan.

- Via the PsychArchives repository: Supplementary Materials. The Supplementary Materials present additional analyses outside of the scope of the main text. These include correlations among variables, examination of ideological and attitude constructs among supporters of each candidate (economic system justification, and anomie), as well as logistic regressions designed to evaluate unique predictors of support for each candidate. We also evaluate similarity of our sample to national Democratic and Republican voters, as well as whether including Buttigieg and Klobuchar supporters under the Biden category affected our results. 


\section{Index of Supplementary Materials}

Womick, J., \& King, L. A. (2021a). Supplementary materials to "Testing cognitive and interpersonal asymmetry vs. symmetry among voters in the 2020 presidential primaries" [Preregistration protocol, data, code, and data analysis plan]. OSF. https://osf.io/97c5g/

Womick, J., \& King, L. A. (2021b). Supplementary materials to "Testing cognitive and interpersonal asymmetry vs. symmetry among voters in the 2020 presidential primaries" [Additional analyses]. PsychOpen GOLD. https://doi.org/10.23668/psycharchives.5198

\section{References}

Adorno, T. W., Frenkel-Brunswik, E., Levinson, D. J., \& Sanford, R. N. (1982). The authoritarian personality. New York, NY, USA: W.W. Norton. (Original work published 1950)

Altemeyer, B. (1998). The other "authoritarian personality." In M. P. Zanna (Ed.), Advances in experimental social psychology (Vol. 30, pp. 47-92). https://doi.org/10.1016/S0065-2601(08)60382-2

Altemeyer, B. (2002). Dogmatic behavior among students: Testing a new measure of dogmatism. The fournal of Social Psychology, 142, 713-721. https://doi.org/10.1080/00224540209603931

Azevedo, F., Jost, J. T., \& Rothmund, T. (2017). “Making America great again”: System justification in the U.S. Presidential election of 2016. Translational Issues in Psychological Science, 3, 231-240. https://doi.org/10.1037/tps0000122

Barberá, P., Jost, J. T., Nagler, J., Tucker, J. A., \& Bonneau, R. (2015). Tweeting from left to right: Is online political communication more than an echo chamber? Psychological Science, 26, 1531-1542. https://doi.org/10.1177/0956797615594620

Brandt, M. H., \& Reyna, C. (2014). To love or hate thy neighbor: The role of authoritarianism and traditionalism in explaining the link between fundamentalism and racial prejudice. Political Psychology, 35, 207-223. https://doi.org/10.1111/pops.12077

Broockman, D. E., \& Kalla, J. L. (2020). Research note: Candidate ideology and vote choice in the 2020 US Presidential Election. OSF Preprints. https://doi.org/10.31219/osf.io/25wm9

Campbell, T. H., \& Kay, A. C. (2014). Solution aversion: On the relation between ideology and motivated disbelief. fournal of Personality and Social Psychology, 107, 809-824. https://doi.org/10.1037/a0037963

Carney, D. R., Jost, J. T., Gosling, S. D., \& Potter, J. (2008). The secret lives of liberals and conservatives: Personality profiles, interaction styles, and the things they leave behind. Political Psychology, 29, 807-840.

https://doi.org/10.1111/j.1467-9221.2008.00668.x

Chambers, J. R., Schlenker, B. R., \& Collisson, B. (2013). Ideology and prejudice: The role of value conflicts. Psychological Science, 24, 140-149. https://doi.org/10.1177/0956797612447820

Choma, B. L., Hafer, C. L., Dywan, J., Segalowitz, S. J., \& Busseri, M. A. (2012). Political liberalism and political conservatism: Functionally independent? Personality and Individual Differences, 53, 431-436. https://doi.org/10.1016/j.paid.2012.04.012

Choma, B. L., \& Hanoch, Y. (2017). Cognitive ability and authoritarianism: Understanding support for Trump and Clinton. Personality and Individual Differences, 106, 287-291. https://doi.org/10.1016/j.paid.2016.10.054

Conway, L. G., III, Gornick, L. H., Houck, S. C., Anderson, C., Stockert, J., Sessoms, D., \& McCue, K. (2016). Are conservatives really more simple-minded than liberals? The domain specificity of complex thinking. Political Psychology, 37, 777-798. https://doi.org/10.1111/pops.12304

Costa, P. T., Jr., \& McCrae, R. R. (1992). Revised SEO Personality Inventory (NEO-PI-R) and NEO Five Factor Inventory (NEO-FFI) professional manual. Odessa, FL, USA: Psychological Assessment Resources.

Crawford, J. T., Brandt, M. H., Inbar, Y., Chambers, J. R., \& Motyl, M. (2017). Social and economic ideologies differentially predict prejudice across the political spectrum, but social issues are most divisive. fournal of Personality and Social Psychology, 112, 383-412. https://doi.org/10.1037/pspa0000074

Crawford, J. T., Brandt, M. J., Inbar, Y., \& Mallinas, S. R. (2016). Right-wing authoritarianism predicts prejudice equally toward 'gay men and lesbians' and 'homosexuals'. Journal of Personality and Social Psychology, 111(2), e31-e45.

https://doi.org/10.1037/pspp0000070

Detrow, S. (2019, December 11). Grassroots progressive group gives Warren top marks among 2020 Democrats. National Public Radio. Retrieved from https://www.npr.org/2019/12/11/786856324/grassroots-progressive-group-gives-warren-top-marks-among-2020-democrats 
Ditto, P. H., Liu, B. S., Clark, C. J., Wojcik, S. P., Chen, E. E., Grady, R. H., Celniker, J. B., \& Zinger, J. F. (2019). At least bias is bipartisan: A meta-analytic comparison of partisan bias in liberals and conservatives. Perspectives on Psychological Science, 14(2), 273-291. https://doi.org/10.1177/1745691617746796

Feldman, S. (2003). Enforcing social conformity: A theory of authoritarianism. Political Psychology, 24, 41-74. https://doi.org/10.1111/0162-895X.00316

Frimer, J. A., Skitka, L. J., \& Motyl, M. (2017). Liberals and conservatives are similarly motivated to avoid exposure to one another's opinions. Journal of Experimental Social Psychology, 72, 1-12. https://doi.org/10.1016/j.jesp.2017.04.003

Gampa, A., Wojcik, S. P., Motyl, M., Nosek, B., \& Ditto, P. H. (2019). (Ideo)Logical reasoning: Ideology impairs sound reasoning. Social Psychological \& Personality Science, 10, 1075-1083. https://doi.org/10.1177/1948550619829059

Greenberg, J., \& Jonas, E. (2003). Ideological motives and political orientation - The Left, the right and the rigid: Comment on Jost et al. (2003). Psychological Bulletin, 129, 376-382. https://doi.org/10.1037/0033-2909.129.3.376

Haran, U., Ritov, I., \& Mellers, B. A. (2013). The role of actively open-minded thinking in information acquisition, accuracy, and calibration. Judgment and Decision Making, 8, 188-201.

Hasson, Y., Tamir, M., Brahms, K. S., Cohrs, J. C., \& Halperin, E. (2018). Are liberals and conservatives equally motivated to feel empathy toward others? Personality and Social Psychology Bulletin, 44, 1449-1459. https://doi.org/10.1177/0146167218769867

Hibbing, J. R., Smith, K. B., \& Alford, J. R. (2013). Predisposed: Liberals, conservatives, and the biology of politics. New York, NY, USA: Routledge.

Hirsh, J. B., DeYoung, C. G., Xu, X., \& Peterson, J. B. (2010). Compassionate liberals and polite conservatives: Associations of agreeableness with political ideology and moral values. Personality and Social Psychology Bulletin, 36, 655-664. https://doi.org/10.1177/0146167210366854

Jost, J. T. (2006). The end of the end of ideology. The American Psychologist, 61, 651-670. https://doi.org/10.1037/0003-066X.61.7.651

Jost, J. T. (2017). Ideological asymmetries and the essence of political psychology. Political Psychology, 38, 167-208. https://doi.org/10.1111/pops.12407

Jost, J. T., Glaser, J., Kruglanski, A. W., \& Sulloway, F. J. (2003). Conservatism as motivated social cognition. Psychological Bulletin, 129, 339-375. https://doi.org/10.1037/0033-2909.129.3.339

Jost, J. T., Sterling, J., \& Stern, C. (2018). Getting closure on conservatism, or the politics of epistemic and existential motivation. In C. E. Kopetz \& A. Fishbach (Eds.), The Motivation-cognition interface: From the lab to the real world. A festschrift in honor of Arie W. Kruglanski (pp. 56-87). New York, NY, USA: Routledge/Taylor \& Francis.

Jost, J. T., West, T. V., \& Gosling, S. D. (2009). Personality and ideology as determinants of candidate preferences and "Obama conversion" in the 2008 U.S. presidential election. Du Bois Review, 6, 103-124. https://doi.org/10.1017/S1742058X09090109

Kruglanski, A. W., \& Webster, D. M. (1996). Motivated closing of the mind: “Seizing” and "freezing." Psychological Review, 103, $263-283$. https://doi.org/10.1037/0033-295X.103.2.263

Ludeke, S. G., Klitgaard, C. N., \& Vitriol, J. (2018). Comprehensively-measured authoritarianism does predict vote choice: The importance of authoritarianism's facets, ideological sorting, and the particular candidate. Personality and Individual Differences, 123, 209-216. https://doi.org/10.1016/j.paid.2017.11.019

Martin, J. (2019, December 16). Elizabeth Warren and Bernie Sanders have a problem: Each other. New York Times. Retrieved from https://www.nytimes.com/2019/12/16/us/politics/elizabeth-warren-bernie-sanders-democrats-2020.html

Mook, D. G. (1983). In defense of external invalidity. The American Psychologist, 38, 379-387. https://doi.org/10.1037/0003-066X.38.4.379

Norris, P. (2020). Measuring Populism Worldwide. (HKS Working Paper No. RWP20-002). https://www.hks.harvard.edu/publications/measuring-populism-worldwide

Onraet, E., Van Hiel, A., Dhont, K., Hodson, G., Schittekatte, M., \& De Pauw, S. (2015). The association of cognitive ability with rightwing ideological attitudes and prejudice: A meta-analytic review. European fournal of Personality, 29, 599-621. https://doi.org/10.1002/per.2027

Phelps, E. (2019, December 11). Indivisible releases presidential candidate scorecard. Indivisible. Retrieved from https://indivisible.org/statement/indivisible-releases-presidential-candidate-scorecard

Pommier, E., Neff, K. D., \& Tóth-Király, I. (2020). The development and validation of the Compassion Scale. Assessment, 27(1), 21-39. https://doi.org/10.1177/1073191119874108

Rollwage, M., Dolan, R. J., \& Fleming, S. M. (2018). Metacognitive failure as a feature of those holding radical beliefs. Current Biology, 28, 4014-4021. https://doi.org/10.1016/j.cub.2018.10.053 
Schraw, G., Bendixen, L. D., \& Dunkle, M. E. (2002). The development and validation of the Epistemic Belief Inventory. In B. K. Hofer \& P. R. Pintrich (Eds.), Personal epistemology: The psychology of beliefs about knowledge and knowing (pp. 261-275). Mahwah, NJ, USA: Lawrence Erlbaum Associates.

Sibley, C. G., Wilson, M. S., \& Duckitt, J. (2007). Antecedents of men's hostile and benevolent sexism: The dual roles of social dominance orientation and right-wing authoritarianism. Personality and Social Psychology Bulletin, 33, 160-172. https://doi.org/10.1177/0146167206294745

Spreng, N. R., McKinnon, M. C., Mar, R. A., \& Levine, B. (2009). The Toronto Empathy Questionnaire: Scale development and initial validation of a factor-analytic solution to multiple empathy measures. fournal of Personality Assessment, 91, 62-71. https://doi.org/10.1080/00223890802484381

Stanley Budner, S. (1962). Intolerance of ambiguity as a personality variable. fournal of Personality, 30, $29-50$. https://doi.org/10.1111/j.1467-6494.1962.tb02303.x

Stefurak, J., Taylor, C., \& Mehta, S. (2010). Gender-specific models of homosexual prejudice: Religiosity, authoritarianism, and gender roles. Psychology of Religion and Spirituality, 2, 247-261. https://doi.org/10.1037/a0021538

Tetlock, P. E. (1983). Cognitive style and political ideology. fournal of Personality and Social Psychology, 45, 118-126. https://doi.org/10.1037/0022-3514.45.1.118

Thomsen, L., Green, E. G. T., \& Sidanius, J. (2008). We will hunt them down: Social dominance orientation and right-wing authoritarianism fuel ethnic persecution of immigrants in fundamentally different ways. fournal of Experimental Social Psychology, 44, 1455-1464. https://doi.org/10.1016/j.jesp.2008.06.011

Toner, K., Leary, M. R., Asher, M. W., \& Jongman-Sereno, K. P. (2013). Feeling superior is a bipartisan issue: Extremity (not direction) of political views predicts perceived belief superiority. Psychological Science, 24, 2454-2462. https://doi.org/10.1177/0956797613494848

Van Hiel, A., Onraet, E., \& De Pauw, S. (2010). The relationship between social-cultural attitudes and behavioral measures of cognitive style: A meta-analytic integration of studies. Journal of Personality, 78, 1765-1799. https://doi.org/10.1111/j.1467-6494.2010.00669.x

Weise, D. R., Arciszewski, T., Verlhiac, J., Psyzczynski, T., \& Greenberg, J. (2012). Terror management and attitudes towards immigrants: Differential effects of mortality salience for low and high Right-Wing Authoritarians. European Psychologist, 17, 63-72. https://doi.org/10.1027/1016-9040/a000056

Womick, J., Rothmund, T., Azevado, F., King, L. A., \& Jost, J. T. (2019). Group-based dominance and authoritarian aggression predict support for Donald Trump in the 2016 U.S. presidential election. Social Psychological \& Personality Science, 10(5), 643-652. https://doi.org/10.1177/1948550618778290

Yilmaz, O., \& Saribay, S. A. (2017). The relationship between cognitive style and political orientation depends on the measures used. fudgment and Decision Making, 12, 140-147.

Zmigrod, L., Rentfrow, P. J., \& Robbins, T. W. (2020). The partisan mind: Is extreme political partisanship related to cognitive inflexibility? fournal of Experimental Psychology. General, 149, 407-418. https://doi.org/10.1037/xge0000661 